\title{
Digital Logistics Capability: Factors Impacting Technology Acceptance
}

\author{
By \\ Tiffany Strom, University of Maryland Global Campus \\ Ilene McCoy, University of Maryland Global Campus \\ Donna W. Jordan, University of Maryland Global Campus \\ Keni Galmai, University of Maryland Global Campus \\ Denise Breckon, University of Maryland Global Campus
}

The Naval Air Warfare Center Aircraft Division Logistics Competency is implementing new technology that will transform the way that logistics analysis is performed. Implementing technology can be a challenge for organizations and especially when the technology disrupts the existing logistics processes. Some of the workforce may view the use of digital devices as frustrating and are likely to be reluctant to accept the new technology even with its enhanced benefits that improve logistics. Through the theoretical lens of the technology acceptance model, this research explores higher order themes using a systematic review and thematic synthesis to identify the factors impacting a user's perceptions of the technology and how their perceptions influence
The Naval Air Warfare Center Aircraft Division Logistics Competency is concerned with the willingness of their employees to accept and implement digital technology that will transform the analysis of logistics data. The technology acceptance model helps explain the importance of user perceptions in their intention to implement the technology. acceptance. A user's acceptance is influenced by their perceptions of the complexity and usability of the technology, leadership's demonstrated support of the technology, and self-perceptions of self-efficacy and trust. Managers should introduce the technology with a positive attitude, choose early adopters to influence peers, and provide tailored training according to the user's comfort and perceptions to increase trust and increase acceptance.

Keywords: Technology acceptance, TAM, user perceptions, trust, organizational alignment, digital processes, logistics, case study

Copyright \ 2019, Tiffany Strom, Ilene McCoy, Donna W. Jordan, Keni Galmai, Denise Breckon. This article is published under a Creative Commons BY-NC license. Permission is granted to copy and distribute this article for non-commercial purposes, in both printed and electronic formats 
Organizations are continually implementing capabilities to improve business outcomes. Many of these improvements center on information technology that can transform business processes and business operations. However, implementing new technology has its risks as many factors serve as barriers to successful implementation. The Naval Air Warfare Center Aircraft Division (NAWCAD), a product center within the U. S. Navy, is preparing to implement a digital logistics platform, known as the Logistics Integrated Virtual Environment or LIVE. A scholar-practitioner doctoral program released a call for organizations to propose organizational problems to be addressed by academic researchers. Meetings with the stakeholder client organization provided insight into their organizational problems. A primary concern for the organization was the acceptance of the technology by their multigenerational population. The researchers initiated an organizational assessment using the strengths, weaknesses, opportunities and threats framework, followed by a research proposal that was negotiated with and agreed to by the client. This case study looked at the organizational problem through the theoretical framework of the technology acceptance model and identified factors that influence a user's decision to use technology. The research used a systematic review to identify the most relevant evidence and shared recommendations with the organization based on the research findings.

\section{Technology Acceptance Model}

NAWCAD's goal is to have their multigenerational workforce accept and use the integrative digital logistics technology. The technology acceptance model (TAM) is used as the theoretical framework to explain the factors that influence the use of new technology, specifically on the user's acceptance and willingness to use the new capability. The model pro- poses two user beliefs: (a) the perceived usefulness, that is "the degree to which a piece of technology will affect a person's job performance" (Venkatesh \& Davis, 2000, p. 191); and (b) perceived ease of use, described as "the degree to which a person believes that a system will be free of physical and mental effort" (Venkatesh \& Davis, 2000, p. 192). These beliefs are the primary determinants for explaining a user's acceptance. The user's decision to accept and use the new capability is identified in the model as the user's behavioral intention. Other external variables, such as forced adoption and culture, are factors that influence a user's perceptions. In this study, user behavior refers to the degree of technology acceptance by NAWCAD employees. The shaded areas in Figure 1 depict the constructs of the TAM used to develop the research question as adapted to NAWCAD's context. Studies on the implementation of technology in digital logistics are emerging as the logistics' industry continues to experience rapid changes due to technology; however, studies in technology acceptance are well established (Venkatesh, Morris, G. Davis, \& F. Davis, 2003). The TAM is recognized in the literature as having potential for practitioners to predict usefulness for applications and attitudes towards technology acceptance (Chau, 1996; Lederer, Maupin, Sena, \& Zhuang, 2000; Venkatesh \& Davis, 2000) and has been one of the most tested theories in the last two decades (Chuttur, 2009) within multiple systems - including medical, enterprise resource planning (ERP), customer service resource (CSR), and standard accounting package (SAP) (Evangelista, Mogre, Perego, Raspagliesi, \& Sweeney, 2012; Kishore \& McLean, 2007; Venkatesh, Morris, G. Davis, \& F. Davis, 2003). The TAM is based on a user's perceptions of use and perceived ease of use as indicators for increasing acceptance. An area that has the potential to influence acceptance that is not addressed in the model is user attitude toward

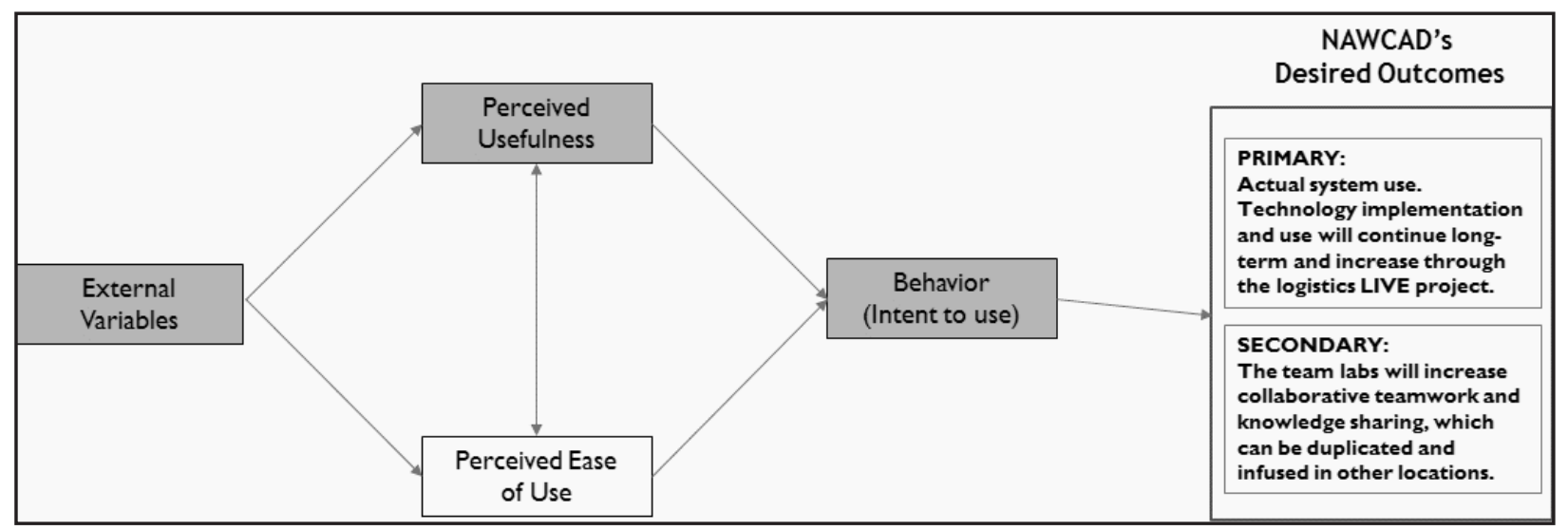

Figure 1. Conceptual model for theoretical framework. This figure illustrates the application of the conceptual technology acceptance model (TAM) for the LIVE project. Adapted from "A Theoretical Extension of the Technology Acceptance Model: Four Longitudinal Field Studies" by V. Venkatesh, and F. D. Davis, 2000, Management Science, 46(2), 186-204. doi: 10.1287/mnsc.46.2.186.11926. 
technology (Chuttur, 2009). Some researchers have recommended that the theory of planned behavior be integrated into the TAM as it can aid in understanding the role of attitude in technology acceptance (Pavlou \& Fygenson, 2006). Where possible, this study investigated aspects of perceptions and attitudes during the literature search; however, it is noted as a limitation to this research as the inclusion of attitude bears further study. The use of the TAM is relevant to this case study as it is a well-established and tested theory as indicated by the vast literature.

\section{Alternative Views \\ In addition to the TAM, alternative views were as- sessed for viability. An alternative reviewed was Kotter's 8-Step model of change, with a focus on the final three steps (create short term wins, don't let up, and make change stick) similar to implementation (Anderson \& Anderson, 2010). This path appeared to be redundant to the awareness, desire, knowl- edge, ability, reinforcement (ADKAR) change mod- el already in place at NAWCAD. ADKAR focuses on activities that drive individual change (Hiatt, 2018). However, the change management processes are not} specifically focused on accepting new technology and do not shed light as to the other factors that influence technology acceptance. To determine what contributes to acceptance, we examined what is integral for technology acceptance in the organizational setting.

Pieces of Everett Rogers' (2003) innovation theories were incorporated as they reinforced aspects of the technology acceptance model and were used to support the research findings further. Rogers' diffusion of innovation theory presents the process of adopting a new idea, technology, process, or product using a bell-shaped curve that shows the adopters of an innovation in five categories; innovators, early adopters, early majority, late majority, and laggards (Rogers, 2003). The innovators typically represent a very small percentage of the innovation adopters but are the quickest to understand and apply their technical knowledge toward the new technology. As a result, innovators are often used to help train their peers (Rogers, 2003). The early adopters are a slightly larger category of those that want to be the first to use the new technology (Rogers, 2003). Early adopters should serve as role models and be respected by their peers in the organization. Through peer networks, these early adopters can help to spur others to adopt the innovation or new technology. Rogers (2003) also discussed the importance of two types of communication channels: mass media and in- terpersonal. The early adopter evaluations of a new technology have the potential to be a very influential interpersonal communication channel and factor in its acceptance.

\section{Naval Air Warfare Center Aircraft Division (NAWCAD) Logistics Competency}

NAWCAD supports research and development, engineering, testing and evaluation of all Navy and Marine Corps air vehicle systems and trainers and provides a variety of services to the Department of Defense, federal agencies, and non-federal customers. As one of two product centers within Naval Air Systems Command (NAVAIR), NAWCAD partners with industries to deliver high-quality, affordable products in support of military operating forces worldwide with their primary purpose being to provide and support military readiness (Naval Air Systems Command, 2018). The organization utilizes a competency aligned infrastructure with integrated product teams comprised of engineers, logisticians, budget and financial managers, contract managers, program managers, etc., who work in support of specific programs. This case study specifically addressed emergent technology acceptance and use by the logisticians.

The logisticians are organizationally aligned by competency and responsible for life cycle support and sustainment from product acquisition, to fielding and maintaining, to disposal across the many different aircraft and weapon system platforms. The total workforce count within NAWCAD's Logistics Competency is 1126, with 721 of those employees at the Patuxent River location (L. Rodriguez, personal communication, April 9, 2018). Baby Boomers are the largest demographic in the workforce; the majority of the employees are between 51-60 years of age with average length of employee service being 10 years with little attrition due to retirement and other career opportunities. NAWCAD logistics competency hires many employees with prior military service reflected in the average age and length of employee service. The workforce projection on retirement eligibility shows less than $5 \%$ will be eligible this year and next (Naval Air Systems Command, 2018).

NAWCAD is preparing to implement new technology to move their logistics' processes to a digital platform that will drive a more integrative, collaborative approach to analyzing logistics information while also fostering employee cross-training for improved workforce agility. NAWCAD currently uses an internally developed data aggregation system to manage 
and track existing logistics information. Their ultimate goal, through the new technology, is to manage logistics through predictive analytics. The first step in this process is taking logistics digital, using an environment known as the Logistics Immersive Virtual Environment (LIVE), where organizational work processes support a collaborative culture within the LIVE workspace. Using digital tools in a new collaborative laboratory workspace, LIVE is designed to drive a more integrated approach to logistics through the cross-training of logisticians, operators, and program managers. The LIVE laboratory will reside at the Patuxent River location where the predominance of the logisticians work.

The work environment is comprised of employees across four generations; referred to as Generation Y (Millennials), Generation X, Baby Boomers, and Traditionalists (Silent Generation). Primarily the technology environment that surrounded them through their childhood on can identify each generation; therefore, it is expected that a workforce of mixed generational employees adds an additional level of complexity to the technology acceptance and implementation process. The organization's vision is for entry-level (Millennial) technical employees (mathematicians, statisticians, mechanical and electrical engineers) to teach more mature (Baby Boomer) less technical employees (logisticians, analysts) how to use the tools and to demonstrate the benefits of using the digital platform. Conversely, the less technical employees will cross-train the newer technical employees on logistics' processes.

Based on information gathered from NAWCAD's long-term objectives, a strategic planning and analysis tool that identified strengths - weaknesses opportunities - threats (SWOT) was used to focus the research efforts. The SWOT analysis can be used to help an organization to formulate strategy by reviewing an organization's strengths, weaknesses, opportunities and threats: the primary goal is to search for opportunities that match with strengths while addressing and mitigating weaknesses. The NAWCAD SWOT analysis, see figure 2, identified: (a) Strengths - existing customer relationships, logistics management experience, hierarchical structure with known expectations; (b) Opportunities - digitization of additional workflow processes, additional funding to refine best practices and expand to other units, better collaborative networks and enhanced partner choices; (c) Weaknesses - attracting and retaining technical workers, command and comply environment, hierarchical structure with less flexibility; and (d) Threats - subject matters experts recruited away by competitors, potential low client adoption, and delayed launch may impact speed to market and available resources. NAWCAD has plans in place to address the attraction and retention of the technical workforce issue which was identified as a weakness,

\section{INTERNAL}

\section{STRENGTHS:}

- Existing customer relationships (closed) market

- Logistics management experience

- Hierarchal structure = known standards/expectations

\section{EXTERNAL}

OPPORTUNITIES:

- Digitization additional workflow processes

- Seek additional funding to refine best practices for expansion to other government units

- Better collaborative networks \& enhanced partner choices

THREATS:

WEAKNESSES:

- Attracting \& retaining technical workers

- Command and comply environment

- Hierarchal structure = less flexibility
- Subject matter experts recruited by competitors

- Potential low client adoption

- Delayed launch may impact speed to market - impacting resources

Figure 2. Strengths, weaknesses, opportunities, and threats (SWOT) analysis for the Naval Air Warfare Center Aircraft Division. Template adapted from LIU Post, 2019. 


\section{Methodology}

According to Yin (1984), a case study is an empirical research methodology that provides an analysis of current phenomenon within a specific context (e.g., person or organization) through the application of concepts, constructs and dynamics and are practical when various evidence sources are used to address a descriptive or explanatory question. The logic from the theoretical framework established in this case study and the solutions provided may then contribute to analytic generalizations relevant and applicable to other entities (Yin, 2012). The more we understand factors shaping new technology implementation, adoption and usage, the better prepared managers are to develop effective courses of action.

The initial research question - What factors in implementing new technology affect its usage in a multigenerational work environment? - was revised after an initial round of research and analysis conducted during four rapid evidence assessments (REAs). A REA uses a targeted, structured review of the literature that is rigorous but not as exhaustive as a full systematic review and can be completed by one person within a few weeks. Though many of the studies in this REA note clear differences amongst the generations, the research provides evidence that there are many common, non-generation specific factors that impact collaboration and knowledge sharing in multigenerational teams. According to Čič and Žižek (2017), the problems typically associated with the 'generation gap' are much smaller than claimed as they are typically based on unsubstantiated claims and stereotypes, and activities that promote intergenerational cooperation (adapting training and motivation specific to the age group; succession planning; employee engagement; various communication channels; leading by example) work to overcome these stereotypes and create greater tolerance, cooperation, and understanding between the generations. The REA research found that collaboration and knowledge sharing are primarily based on individual and environmental factors rather than generational characteristics; therefore, the literature search included but was not limited to studies within a multigenerational environment. The revised research question that guided this case study was: What organizational factors impact new technology acceptance in a work environment? Using the CIMO method - Context, Intervention, Mechanism, and Outcome - formulated for the social sciences, the research question can be made specific and guide the research as it takes into consideration how the relationship between factors occurs and under what circumstances specific to the situation (Briner, Denyer, \& Rousseau, 2009).

The review team identified and grouped potential barriers to the technology implementation as environmental, organizational and individual factors that included: (a) mandatory adoption (environmental factor); (b) a multigenerational workforce (environmental and generational factors); (c) change - technology implementation (organizational factor); and (d) organizational trust and perceived support (organizational and individual factors). This case study examined these factors using a systematic review. Systematic reviews are used to inform management practice by identifying the most relevant and credible research evidence through a rigorous protocol that includes a systematic search using targeted key words across a variety of library databases that is scoped to the key literature using established exclusion criteria (Barends, et al., 2014; Briner \& Denver, 2012). Next, a quality assessment of the literature was done to determine the rigor and relevance of each study in answering the research question prior to the evidence from the studies being analyzed and synthesized. The findings for this case were developed from the thematic synthesis of 20 studies of mixed research designs that were identified as being relevant to understanding differing perspectives of technology implementation - from the role of environment based voluntariness, to the impact of pre-implementation expectations of use, to the effects of source credibility and argument quality on employees' responses to the technology. The research was briefed to the organization via a presentation to gain feedback and perspective on the findings. A final set of findings and recommendations were incorporated into a report that was delivered to the organization.

and the expressed support of the command structure will help with the environmental challenges. The threat of potentially losing subject matter experts to competitors is being addressed through retention initiatives and was viewed as minimal due to low attrition rates. The remaining two threats of low client adoption and delayed launch of the new capability are related to the LIVE implementation.

\section{Findings and Discussion}

Quirkos, a qualitative software tool that helps sort, manage and understand textual data (Quirkos, 2017), was used to aid in the first and second-cycle coding of the literature. The data from the 20 studies were regrouped into five primary themes; organizational alignment, organizational perception, 
early adopters, employee perceptions, and trust. The coding of core themes identified the perceptions of user, leadership, and technology as the factors that influenced technology acceptance. The overarching theme of trust was an indicator that ran across studies.

\section{User's perceptions of self}

Perceptions of the user influenced technology acceptance. A technology ready user with high self-efficacy and a positive attitude was more likely to accept the new technology, especially if they viewed it as being able to benefit their performance. Employee perceptions need to be positive to have a positive effect on technology acceptance. If the perceptions are positive, e.g., if the technology is believed to benefit employee performance and there is social pressure to change, technology acceptance will increase (Rhoades \& Eisenberger, 2002). The ideal user should have high self-efficacy, be technology ready and be excited about training (Lin, Shih, \& Sher, 2007). Trust is a portion of the individual theme. Employees must trust the IT staff and that the team leader is knowledgeable. Finally, at the individual level, the use of early adopters is necessary to improve technology acceptance (Shadur, Kienzle, \& Rodwell, 1999). An early adopter that is excited about the new system and implementation can infuse the technology quicker and reduce the perceived complexity of the system. Three studies identify early adopters based on their technology-based products or applications (Obal, 2013; Rhoades \& Eisenberger, 2002; Walter \& Lopez, 2008). This identification is critical because early adopters often serve as opinion leaders and influence the adoption decisions of those who adopt later. However, when employees perceived the technology as complex, and not being effective for the task or not being compatible with existing work, the likelihood of acceptance decreased.

\section{User's perception of leadership}

Another factor influencing technology acceptance was the user's perceptions of leadership. The leadership themes that contributed to organizational alignment are leadership perceptions, expert knowledge, and training. When leaders displayed a positive attitude and actively listened to the employees, the likelihood of technology acceptance increased. Users look to leadership and trust that they are knowledgeable. Providing these facets increases technology acceptance. The literature states that first and foremost, leaders need to display a positive attitude toward the project at hand; this includes a positive attitude and actively listening to the users (Rhoades \& Eisenberger, 2002). The leader has to remember there are users on board who are current with the technology; users that are aware but are non-users of the technology; and users that are unaware. Leadership has to provide expert knowledge, along with sufficient training for the new system (Walter \& Lopez, 2008). Leaders need to be aware of the various levels of knowledge and exposure that employees have toward the new technology and provide information and targeted training by experts according to the needs of each user group (Rhoades \& Eisenberger, 2002; Shibel, Lawley, \& Debuse, 2012; Walter \& Lopez, 2008). Employees with more years with the organization may be less receptive to technology changes than those who are less tenured (Saeed, Abdinour, Lengnick-Hall, \& Lengnick-Hall, 2010). Leader behaviors can influence the likelihood of their employees accepting the new technology such as demonstrating their support for the new technology in forums and announcements, having a strategic implementation plan, answering questions and concerns as they arise, selecting and grooming early adopters, and spending additional time to actively engage those employees with longer tenure to encourage their acceptance.

\section{User's perception of technology}

Another factor influencing technology acceptance was the user's perception of the technology. The technology themes that contributed to organizational alignment are technology perceptions, compatibility, infusion, and long term acceptance. When users perceived the technology as being an extension of the job function and a good fit for the organization, the likelihood of employees accepting the technology increased. Negative perceptions of the technology system can be reduced with leadership and early adopters having a positive attitude. It is important that technology is specified properly for the context of the organization or compatibility. If the technology is seen as an extension of the job function, use will increase. If the technology is not a fit for the organization, the user will not use the product. The evidence showed that, even at the expert level, there would be decreased use when the new tool is not effective or efficient (Brandon-Jones \& Kauppi, 2017). Technology acceptance decreases if complexity in the system is high and individuals do not perceive the relative advantage of the new system.

Use of the new technology is the goal within the final phase of adoption (Copper \& Zmud, 1990; Gallivan, 2001). As such, leadership must recognize that balancing positive perceptions across user, leadership, 
and technology requires a strategic implementation plan that includes environmental, organizational and individual factors that foster successful implementation (DeLone \& Mclean, 2003). Effective implementation plans address long-term adoption planning and interventions to reduce barriers (Cooper \& Zmud, 1990). Environmental factors include culture and competition; organizational factors include early adopters and positive leaders; and individual factors include demographics and personal values (Varabyova et al., 2017).

Several actions were identified as factors that mitigated negative perceptions or moderated perceptions. Positive leadership engagement and the use of early adopters reduced the negative perceptions of the technology (Brandon-Jones \& Kauppi, 2017). Early adopters were critical in improving technology acceptance as they reduced the perceived complexity of the technology and infused the technology quicker. (Lin, Shih, \& Sher, 2007; Obal, 2013; Rhoades \& Eisenberger, 2002; Shadur, Kienzle, \& Rodwell, 1999; Walter \& Lopez, 2008; Yi, Jackson, Park \& Probst, 2006). When employees perceive the technology as useful and compatible, they are more likely to perceive it as easier to use and will be more likely to adopt the new technology.

\section{Influence of trust}

An overarching theme of trust was present in $85 \%$ percent of the systematic review literature (17 of 20 articles). Trust in the system, trust in the leadership, trust in the training team, and trust in the organization's decisions positively influenced each of the other relationships (Brandon-Jones \& Kauppi, 2017; Brown, Dennis, \& Venkatesh, 2010; Hernández-Ortega, 2011; Rhoades \& Eisenberger, 2002; Schepers \& Wetzels, 2007). Where trust was higher, technology acceptance increased. Trust moderates the entire model as each relationship is affected positively or negatively with or without it. One example is, if the employee trusts the IT staff and trusts that the team leader is knowledgeable, then trust is high which leads to higher technology acceptance. The literature examined the influences of trust when examining user acceptance of IT (Brandon-Jones \& Kauppi, 2017; Brown, Dennis, \& Venkatesh, 2010; Rhoades \& Eisenberger, 2002). These findings also empirically define how trust can be positively related to personal experience in using IT programs (Schepers \& Wetzels, 2007) and the importance of post-use trust in technology acceptance (Hernández-Ortega, 2011).

All of the studies contributed by validating a diverse set of consistent, literature-based trust measures and by demonstrating the acceptance of technology requires not only that the organization perceives ease of use and security during its implementation, but also that managers should show a positive attitude towards the deployment of the technology. The literature supports that leaders should act as champions of technological innovation to encourage the development and acceptance of new technology by the workforce.

\section{Conceptual Model}

Organizational Alignment (OA) is the goal of technology implementation where individual and organizational needs meet (Kishore \& McLean, 2007). In order to achieve OA, the following components should be present: relative advantage (rapid rate of adoption) - not addressed in this study; voluntariness or freedom to adopt; infusion (long-term goal) of the technology in the organization - not addressed in this study; perceived organizational support; commitment by the organization; positive attitude at both the employee and leader levels. The thematic coding confirms that these facets have to align to achieve technology acceptance. Based on the coding and grouping of the categories (as shown in the conceptual model) three overarching themes emerged; all impacted by organizational factors and bound by trust.

The TAM framework is important because the goal of the organization is technology acceptance as a result, individual acceptance should be viewed first, then organizational acceptance. The evidence shows that users' perceptions of new systems are complex and, if not supported by management or if proper training is not provided, technology acceptance is reduced. According to McKnight, Choudhury, and Kacmar (2002), employees need to trust IT personnel and management in addition to having organizational support. Organizational leaders can improve the implementation of new technology by increasing trust, where trust is a belief in an attribute of or willingness to believe the trustee (McKnight, Choudhury, \& Kacmar, 2002).

Without trust, perceptions may be negative and result in relationships that impede the effectiveness of system adaptation. Therefore, the conceptual model depicted in figure 3 represents the integration of the perceptions of the individual, leader, and technology that contribute to the overall organizational acceptance of the technology. By positively influencing the inputs of these perceptions and organizational factors, the behavioral output of intention of technology acceptance is increased. This conceptual mod- 


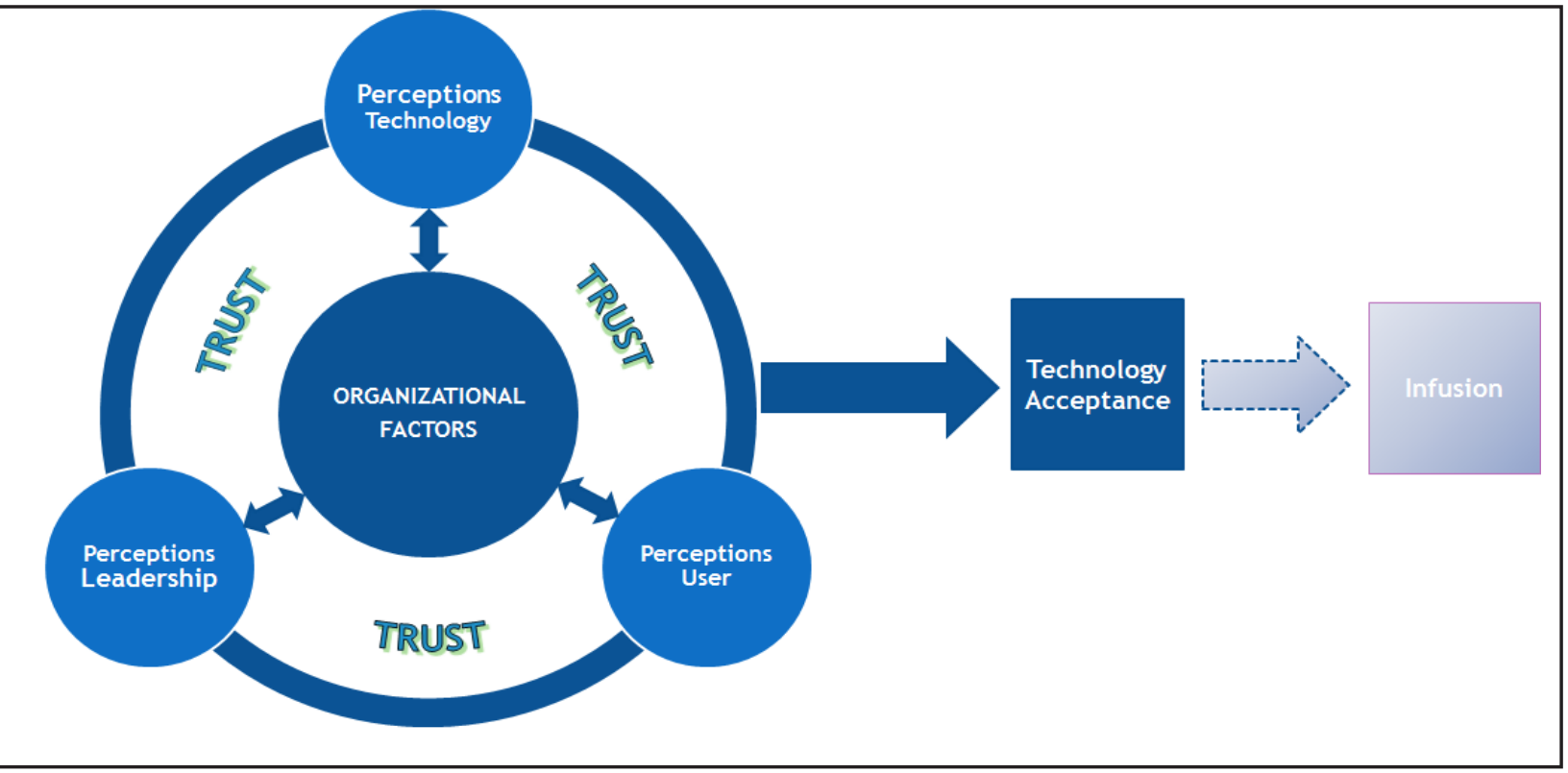

Figure 3. Conceptual model demonstrating technology implementation through the lens of the theoretical framework of TAM. The integration of the user's perception of users, user's perception of leadership, and user's perception of technology in an organizational environment of trust positively influence technology acceptance (Source: Authors).

el aligns with the TAM as the desired behavior is technology acceptance. Trust was found to influence positive perceptions and fostered technology acceptance and the long-term goal of infusion.

\section{Recommendations}

Though the initial problem statement from NAW$\mathrm{CAD}$ concerned the multigenerational workforce, the evidence-based research process found that although there are differences amongst the generations, multigenerational demographics are likely not a major factor in technology acceptance, and although millennials may accept a new technology more quickly than baby boomers, employees accept technology as they become aware of it and see its benefits. What the systematic review revealed was that the technology acceptance was reduced when the user's perception was that the new system was viewed as complex, management did not support the system, and proper training was not provided. Based on the research and findings, it is important for NAWCAD leaders to engage early users (early adopters) of the new technology to create among them a shared understanding and agreement about the high state of alignment that is expected between the technology and organizational components by the employees and the organization as a whole. Management should communicate and socialize the concept of organizational alignment through training programs, workshops, and other mass media and interpersonal communication channels. Leaders should also have an understanding of factors that shape employee beliefs regarding new information technologies. More specifically, the following recommendations were proposed for NAWCAD to aid in the LIVE implementation:

- Develop and conduct a survey to identify employee levels of technology awareness or readiness (e.g., expert, intermediate, or novice) and preferred learning methods.

- Develop a multi-faceted training plan, based on the survey results, that addresses individual learning preferences rather than generational demographics (e.g., simulation/ virtual, e-manuals, webinars, workshops, etc.).

- Use early adopters as team leaders, training facilitators, and mentors.

- Ensure there is a robust communication plan in place before implementation that provides support at each stakeholder level (management/ leaders, employees, clients).

The NAWCAD logistics competency incorporated the recommendations derived from the research into their implementation plan with some modifications. NAWCAD will plan and facilitate tailored training events with program logisticians and more recently hired technical employees beginning with a pilot program. Those participating in the training will be surveyed before and after the actual training to understand their comfort with and knowledge level of the new technology along with their preferred method of training. Managers will kick off each training event expressing their support for the event and insight as to how the technology aligns 
with the organization's vision and goals. The training will be delivered based on the feedback from the initial survey. Those trainees identified as early adopters and who are seen as having credibility with their peers will continue training with the next group to facilitate their learning. From the recommendations in the study, NAWCAD chose to create an immersive learning environment that will support differing learning styles, methods, and technologies. Implementation continues as the learning environment is still in development. For now, legacy training continues and trainees are surveyed before and after training to gather feedback which will be used to improve the new learning environment and to identify early adopters. Metrics on employee age and length of service will be tracked along with training feedback for later analysis.

\section{Implementation Risks}

The recommendations present implications for leadership, mainly in the form of resources (i.e., additional funding, personnel's time). Additionally, the current implementation schedule could require an extension depending on the rate of adoption or other organizational cultural influences (work environment norms and practices) that might impact trust. Lastly, though this case study was based on what was found during a rigorous evidence-based research process, there was no time to develop a measurement instrument (survey) to collect actual field data. Further, there was no ability or time to set up a control group to test possible interventions.

The research is limited in that it has not yet been subjected to replication. Supporting this thought, Rosenzweig and Roth (2007) stated that replication is ultimately the best way to progress research. Consequently, generalizing these results to other organizations without reviewing the context and background should be done with caution. To partially address this issue, retesting the conceptual model in future studies in other organizations, different training programs, and customized implementations may contribute to establishing the generalizability of this study's results.

NAWCAD logistics leadership has been involved in the project from the beginning, championing the technology adoption by delivering personal messages to the workforce touting the value to the employees and the programs they support. Additionally, leadership is answering stakeholder questions and concerns and promising tailored training which is building employee trust in the new digital logistics capability and those implementing it.

\section{Implications for Practice}

Organizations seeking to take full advantage of the innovation and synergy that multigenerational teams create must be willing to construct a multi-faceted approach in addressing factors that impact collaboration and knowledge sharing within these teams. Management's active involvement in leading across generational or other boundaries by establishing an infrastructure that provides the necessary tools for fostering collaboration and trust is essential. $\mathrm{Hu}-$ man resource practices that address specific items such as providing diversity and sensitivity training; rewarding employees based on contributions rather than seniority; establishing formal processes for conflict resolution; providing cross-mentoring opportunities; and providing formal and informal avenues for open and honest feedback can lead to increased communication and trust - factors essential to employees moving from misguided generational stereotypes toward recognizing and appreciating the value of individual skills and experiences that contribute to the collective success of new technology implementation in teams.

Training should be developed based on an employee's level of technology readiness and managers should assess the individual needs of employees rather than assume they have the same needs. Leaders can develop different training plans that are targeted toward technology readiness and preferred learning styles of individuals. A baby boomer employee may prefer virtual training while a Generation Y employee may prefer onsite face to face training so assumptions of learning styles should not be assumed based on generational demographics. Leaders can identify early adopters through surveys or informal conversations. It is beneficial to the organizational acceptance to have early adopters identified across several generations. Leadership engagement and clear communication of goals and objectives of the new technology to all stakeholders is critical to its acceptance and use. Having an awareness of the factors that shape employee beliefs regarding technology allows leaders to tailor their messages and ensure they reach all employees.

\section{Conclusions}

One of the primary challenges to the implementation of new technology is the acceptance by the employees. Managers would typically prefer that employees 
accept and use the new technology voluntarily without having to be forced. NAWCAD leadership's goal is to implement a new digital logistics capability and collaboration space for their workforce. Their generationally diverse workforce has varying levels of comfort with new technology. The purpose of this research was to systematically review the literature regarding technology acceptance and provide recommendations for NAWCAD leaders. Using the technology acceptance model as both a theoretical framework and lens for the research, the resulting conceptual model depicted the interlinkage between perceived usefulness, perceived ease of use, and intent to use and how external variables play a role in its effectiveness. Trust between the organization implementing the change and the individuals who are mandated to adopt the change increased technology acceptance. Organizational support, something that the leadership at NAWCAD has explicitly expressed, is central to creating trust which, in turn, affects perceptions regarding the ease of use and usefulness of the new technology.

\section{References}

Anderson, D., \& Anderson, L. A. (2010). Beyond change management: How to achieve breakthrough results through conscious change leadership. San Francisco, CA: John Wiley \& Sons.

Barends, E., Rousseau, D., \& Briner, R. (2014). Evidence-based management: The basic principles. Amsterdam, The Netherlands: Center for Evidence-Based Management.

Brandon-Jones, A., \& Kauppi, K. (2017). Examining the antecedents of the Technology Acceptance Model within e-procurement. International Journal of Operations \& Production Management, 38(1), 22-42. doi:10.1108/IJOPM-06-2015-0346

Briner, R. B., Denyer, D., \& Rousseau, D. M. (2009). Evidence-based management: Concept cleanup time? Academy of Management Perspective, 23(4), 19-32. doi:10.5465/AMP.2009.45590138

Briner, R. B., \& Denyer, D. (2012). Systematic review and evidence synthesis as a practice and scholarship tool. In D. M. Rousseau (Ed.), The Oxford handbook of evidence-based management (pp. 112-129). Oxford: Oxford University Press. https://doi.org/10.1093/oxford$\mathrm{hb} / 9780199763986.013 .0007$

Brown, S. A., Dennis, A. R., \& Venkatesh, V. (2010). Predicting collaboration technology use: Integrating technology adoption and collaboration research. Journal of Management Information Systems, 27(2), 9-53. doi:10.2753/ MIS0742-1222270201

Chau, P. Y. (1996). An empirical assessment of a modified technology acceptance model. Journal of Management Information Systems, 13(2), 185204. doi:10.1080/07421222.1996.11518128

Čič, Ž. V., \& Žižek, S. Š. (2017). Intergenerational cooperation at the workplace from the management perspective. Our Economy, 63(3), 47-59. doi:10.1515/ngoe-2017-0018

Chuttur, M. Y. (2009). Overview of the technology acceptance model: Origins, developments and future directions. Working Papers on Information Systems, 9(37), 9-37. Retrieved from http:// sprouts.aisnet.org/9-37

Cooper, R. B. \& Zmud, R. W. (1990). Information technology implementation research: A technological diffusion approach. Management Science, 36(2), 123-139. doi:10.1287/mnsc.36.2.123

DeLone, W. H., \& McLean, E. R. (2003). Model of information systems success: A ten-year update. Journal of Management Information Systems. 19(4), 9-30. https://doi.org/10.1080/07421222.20 03.11045748

Evangelista, P., Mogre, R., Perego, A., Raspagliesi, A., \& Sweeney, E. (2012). A survey based analysis of IT adoption and 3PLs' performance. Supply Chain Management: An International Journal, 17(2), 172-186. doi:10.1108/13598541211212906

Gallivan, M. J. (2001). Organizational adoption and assimilation of complex technological innovations: Development and application of a network framework. The Database for Advances in Information Systems, 32(3), 51-85. https://doi. org/10.1145/506724.506729

Hernández-Ortega, B. (2011). The role of post-use trust in the acceptance of a technology: Drivers and consequences. Technovation, 31(10-11), 523538. doi:10.1016/j.technovation.2011.07.001

Hiatt, J. (2018). ADKAR change management model: What is the ADKAR model? In ADKAR change management model overview. Retrieved from https://www.prosci.com/adkar/adkar-model

Kishore, R., \& McLean, E. R. (2007). Reconceptualizing innovation compatibility as organizational alignment in secondary IT adoption contexts: An investigation of software reuse infusion. IEEE Transactions on Engineering Management, 54(4), 756-775. doi:10.1109/tem.2007.906849

Lederer, A. L., Maupin, D. J., Sena, M. P., \& Zhuang, Y. (2000). The technology acceptance model and the World Wide Web. Decision Support Systems, 29(3), 269-282. doi:10.1016/S01679236(00)00076-2

Lin, C. H., Shih, H. Y., \& Sher, P. J. (2007). Integrating technology readiness into technology acceptance: The TRAM model. Psychology \& Marketing, 24(7), 641-657. doi:10.1002/mar.20177 
LIU Post (2019). SWOT Analysis: Define SWOT. Library site of Long Island University. Retrieved from http://liu.cwp.libguides.com/c. php?g=800691\&p=5722103

McKnight, D.H., Choudhury, V., \& Kacmar, C. (2002). Developing and validating trust measures for e-commerce: An integrative typology. Information Systems Research, 13(3), 334-359. doi:10.1287/isre.13.3.334.81

Naval Air Systems Command (NAVAIR). (2018). About us. In Naval Air Warfare Center Aircraft Division. Retrieved from http://www.navair.navy. mil/NAWCAD/index.cfm?fuseaction $=$ home. about_us

Obal, M. (2013). Why do incumbents sometimes succeed? Investigating the role of interorganizational trust on the adoption of disruptive technology. Industrial Marketing Management, 42, 900908. doi:10.1016/j.indmarman.2013.05.017

Pavlou, P. A., \& Fygenson, M. (2006). Understanding and predicting electronic commerce adoption: An extension of the theory of planned behavior. MIS Quarterly, 115-143. doi:10.2307/25148720

Quirkos. (2017). What is Quirkos? In Qualitative data analysis software for everyone: Quirkos makes it easy to understand your text. Retrieved from http://www.quirkos.com

Rhoades, L., \& Eisenberger, R. (2002). Perceived organizational support: A review of the literature. Journal of Applied Psychology, 87(4), 698-714. doi:10.1037/0021-9010.87.4.698

Rosenzweig, E. D., \& Roth, A. V. (2007). B2B seller competence: construct development and measurement using a supply chain strategy lens. Journal of Operations Management, 25(6), 1311-1331. doi:10.1016/j.jom.2007.01.007

Rogers, E. (2003). Diffusion of innovations. Fifth edition. New York: Free Press.

Saeed, K. A., Abdinour, S., Lengnick-Hall, M. L. \& Lengnick-Hall, C. A. (2010). Examining the impact of pre-implementation expectations on post-implementation use of enterprise systems: A longitudinal study. Decision Sciences Journal, 41(4), 659-688. doi:10.1111/j.15405915.2010.00285.x

Schepers, J., \& Wetzels, M. (2007). A meta-analysis of the technology acceptance model: Investigating subjective norm and moderation effects. Informa- tion \& Management, 44(1), 90-103. doi:10.1016/j. im.2006.10.007

Shadur, M. A., Kienzle, R., \& Rodwell, J. J. (1999). The relationship between organizational climate and employee perceptions of involvement: The importance of support. Group \& Organization Management, 24(4), 479-503. doi:10.1177/1059601199244005

Shibel, R., Lawley, M., \& Debuse, J. (2012). Factors influencing decision support system acceptance. Decision Support Systems, 54(2), 953-961. doi:10.1016/j.dss.2012.09.018

Varabyova, Y., Blankart, C. R., \& Schreyögg, J. (2017). The role of learning in health technology assessments: An empirical assessment of endovascular aneurysm repairs in German hospitals. Health Economics, 26(1), 93-108. https://doi. org/10.1002/hec.3466

Venkatesh, V., \& Davis, F. D. (2000). A theoretical extension of the technology acceptance model: Four longitudinal field studies. Management Science, 46(2), 186-204. doi:10.1287/mnsc.46.2.186.11926

Venkatesh, V., Morris, M. G., Davis, G. B., \& Davis, F. D. (2003). User acceptance of information technology: Toward a unified view. MIS Quarterly, 27(3), 425-478. doi: 10.2307/30036540

Walter, Z., \& Lopez, M. S. (2008). Physician acceptance of information technologies: Role of perceived threat to professional autonomy. Decision Support Systems, 46(1), 206-215. doi:10.1016/j. dss.2008.06.004

Yi, M., Jackson, J., Park, J., \& Probst, J. (2006). Understanding information technology acceptance by individual professionals: Toward an integrative view. Information and Management, 43(3), 350-363. doi:10.1016/j.im.2005.08.006

Yin, R. (1984). Case study research: Design and methods. Thousand Oaks, CA: Sage Publications.

Yin, R. (2012). Applications of case study research (3rd ed.). Thousand Oaks, CA: Sage Publications.

\section{Review}

This article was accepted under the strict peer review option. For futher details, see the descriptions at:

http://mumabusinessreview.org/peer-review-options/

Note: The views expressed in this article are those of the authors and do not represent the policy or position of the University of Maryland Global Campus or the Department of Defense. 


\section{Authors}

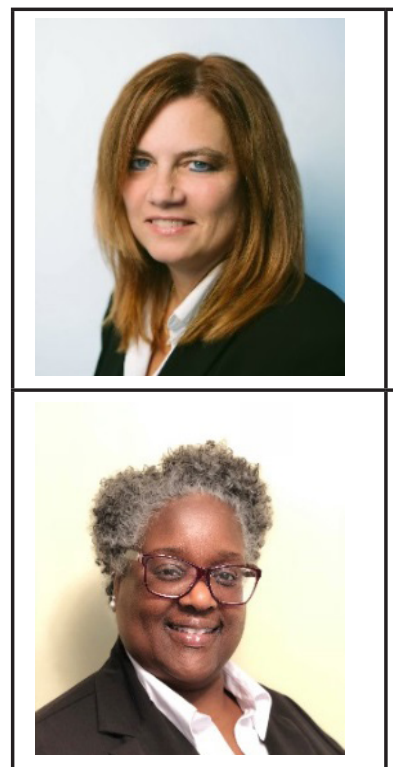

Tiffany Strom is a mission-critical project manager at Miller Engineering Information Technologies, Inc. As a senior consultant and business management professional, she is completing the Doctorate of Business Administration degree. Tiffany holds a BA in Business Management and Professional Communications (double major) from Alverno College, and an MBA with an emphasis in Economics from UW-Whitewater. Her research area of interest is small business management resulting from 24 years of experience in small business, both as a consultant and as a business manager.

Ilene McCoy serves as director and special assistant to the dean of the Krieger School of Arts and Sciences at Johns Hopkins University (JHU), providing administrative and operational support to the dean and senior leadership. Ilene holds a Bachelor of Arts in Administration from Sojourner-Douglass College, a Master of Business Administration from Loyola University, and is currently pursuing a Doctor of Business Administration from University of Maryland Global Campus. Her research areas of interest include developing and managing high-performance teams; resolving interpersonal and team conflict; and establishing effective interdisciplinary teams.



Donna W. Jordan is a Facilities and Real Property Division Chief. Her professional background consists of 30+ years of Facility and Real Property Management Experience with 24 of those years as a civilian with the Department of the Navy. She holds a Bachelor of Science in Mechanical Engineering and a Masters in Engineering Management with concentration in Environmental and Energy Management. She is currently pursuing a Doctor of Business Administration (DBA) degree from the University of Maryland Global Campus. Her study of interest is developing millennials for leadership.

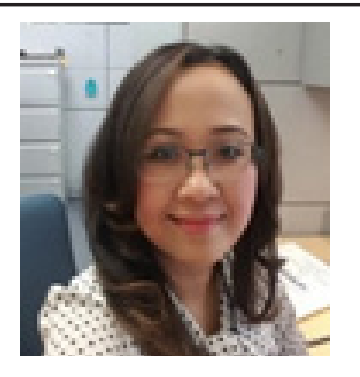

Keni Galmai is a financial management analyst who works to provide a formulation of material budget pricing for Department of Navy. She is Green Belt Six Sigma certified and holds an MBA from the University of Maryland Global Campus. Keni is an active member of the American Society Military Comptrollers and is working towards her CDFM certification in addition to working on her Doctoral degree from the University of Maryland Global Campus. Keni aspires to step into the consulting industry after gaining several years of experience from Federal service. Her research area of interest is helping companies solve problems related to employee hiring and retention.

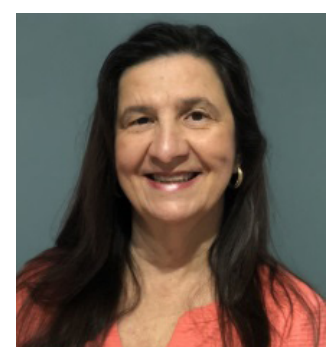

Denise Breckon is Collegiate Faculty at the University of Maryland Global Campus teaching adult professionals to be scholar-practitioners in their fields. After spending 30 years working as an acquisition professional for the Department of Defense, Denise realized that academic research was not findings its way into the management practices - and with a desire to bridge this research-practice gap, she began to teach in the graduate school. Regardless of the course, Denise spends much time igniting her students' passion for research. Denise earned a Bachelor's degree in Electrical Engineering from Penn State and a Masters and Doctorate in Management from the University of Maryland Global Campus. 